\title{
On the Association between Travel Distance and Treatment Choice for Low-Risk Prostate Cancer: Results from a Rural State*
}

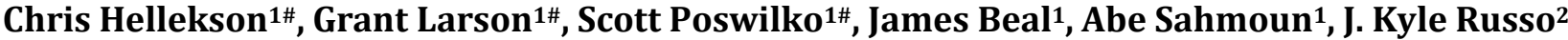 \\ ${ }^{1}$ The University of North Dakota School of Medicine and Health Sciences, Grand Forks, ND, USA \\ ${ }^{2}$ Bismarck Cancer Center, Bismarck, ND, USA \\ Email: Christopher.hellekso@ndus.edu
}

How to cite this paper: Hellekson, C., Larson, G., Poswilko, S., Beal, J., Sahmoun, A. and Russo, J.K. (2016) On the Association between Travel Distance and Treatment Choice for Low-Risk Prostate Cancer: Results from a Rural State. Journal of Cancer Therapy, 7, 656-664.

http://dx.doi.org/10.4236/jct.2016.79068

Received: August 18, 2016

Accepted: September 18, 2016

Published: September 21, 2016

Copyright $\odot 2016$ by authors and Scientific Research Publishing Inc. This work is licensed under the Creative Commons Attribution International License (CC BY 4.0).

http://creativecommons.org/licenses/by/4.0/

\begin{abstract}
Background: Evidence suggests that cancer patients with increased travel burden to treatment centers may have limited treatment options. Purpose: To investigate the association between travel distance to a treatment facility and initial treatment choice among young men with low-risk prostate cancer in a rural state. Methods: A retrospective medical charts review was conducted of young men (65 years or younger) newly diagnosed with low-risk prostate cancer from January 1, 2005 through December 31, 2014 who were treated with either active surveillance, radical prostatectomy, or brachytherapy at either of the two major hospital systems in Bismarck, ND, USA. Results: Information on a random sample of 242 patients was studied. The majority of patients (66\%) received radical prostatectomy. Patients who received radical prostatectomy were significantly younger ( $\mathrm{p}$-value $<0.001)$. PSA at diagnosis, clinical stage, and Gleason score were not associated with treatment choice ( $\mathrm{p}$-value $=0.06 ; \mathrm{p}$-value $=0.1794$; and $\mathrm{p}$-value $=1.00$; respectively). Adjusting for age at diagnosis, PSA at diagnosis, and treatment facility, treatment choice was not associated with travel distance $(\mathrm{p}$-value $=0.309$ ). Patients treated at St. Alexius facility were more likely to undergo radical prostatectomy than Sanford health patients (p-value < 0.0001). Conclusions: We found no association between travel distance and treatment choice for low-risk prostate cancer. Treatment choice was associated with institution which may suggest institutional bias in patterns of care.
\end{abstract}

\section{Keywords}

Low-Risk, Prostate Cancer, Rural, Brachytherapy, Prostatectomy, Young Men, Travel Distance

${ }^{\star}$ Other participating institutions: Bismarck CHI St. Alexius Health Medical Center; Bismarck Sanford Health Medical Center.

"First three authors contributed equally. 


\section{Introduction}

Prostate cancer is the most common cancer among men in the United States, and is one of the leading causes of cancer deaths among men. It is estimated that 180,890 men in the United States (US) will be diagnosed with prostate cancer in 2016, with an associated 26,120 deaths [1]. Eighty-one percent of men have disease confined to the prostate gland (clinically localized disease).

Men with low-risk prostate cancer have a choice between three definitive treatment options: radical prostatectomy $(\mathrm{RP})$, external beam radiation therapy (EBRT), or brachytherapy. Active surveillance (AS) is also an option, particularly among elderly patients or young patients wishing to delay the side effects of definitive therapy [2]. There are no data from randomized clinical trials that compare these approaches in young men with low-risk prostate cancer. In 2012, a large phase III trial (PREFERE) was initiated to compare prostate cancer survival after RP, EBRT, brachytherapy, and AS. This trial will be completed in 2029 [3]. Therefore, the current choice of therapy depends on patient-specific informed decision-making.

Access to treatment centers may be difficult due to travel burden resulting from distance and the lack of public transportation systems in rural areas. These barriers could affect treatment choice for rural patients diagnosed with cancer [4] [5]. Rural residents tend to make fewer trips per day, but travel 38\% more miles than people living in urban areas [6]. Socio-economically disadvantaged people in rural areas travel 59\% more miles per day than their urban counterparts. Poverty level and rural location have been shown to decrease the numbers of physician visits for chronic care [7]. Transportation barriers to care are also associated with reduced adherence to cancer screening [8]. Rural residents were more likely to travel 30 miles or longer for care than urban residents $(21.4 \%$ versus $4.5 \%, \mathrm{p}<0.0001)$ and rural trips took about $31 \%$ longer than urban trips [9]. Muralidhar et al. [10] found that the distance between a patient's residence and their treatment facility significantly influenced the rate at which patients received radiation compared with surgery for localized prostate cancer. Furthermore, patients living in rural areas were one-third as likely to receive radiation if they lived $>75$ miles compared with $\leq 25$ miles from the treatment facility. Others have reported that rural patients with early-stage prostate cancer were significantly less likely than urban patients to receive radical prostatectomy, daily external beam radiation, and brachytherapy [11].

North Dakota (ND), with a total population of approximately 756,927 [12] is the 4 th least populous and the 4 th least densely populated state in the US. "Rural" is generally defined as having a population center of less than 50,000 persons. Major population centers (Bismarck: 71,167; Fargo: 118,523; and Grand Forks: 70,916) have 34\% of the state population. Therefore, ND is one of the most rural states in the US, with almost $2 / 3$ of its population living outside metropolitan areas.

The primary objective of this study was to describe the initial treatment patterns for low-risk prostate cancer in young men; to determine the clinical and patient characteristics associated with initial treatment; and assess the association between travel distance to a treatment facility and initial treatment choice in a rural state. 


\section{Methods and Materials}

A hospital and cancer center based retrospective charts review was conducted of young (65 years or younger) men (242) with a new diagnosis of low-risk prostate cancer (PSA 10 or less, Gleason 6, clinical T stage 2a or lower) from January 1, 2005 through December 31, 2014 who received treatment at one of two major hospital systems: Sanford Health or St. Alexius Medical Center/Mid Dakota Clinic, both located in Bismarck, ND, USA and affiliated with the Bismarck Cancer Center, which was the sole radiation provider for patients included in this study.

Men resided primarily in western and central North Dakota, with a smaller number of patients from north-central South Dakota. Ages ranged from 45 - 64 years. Nonwhite men and those with prior cancer diagnoses were excluded. Demographic, clinical, and treatment data included: age at diagnosis, zip code, CT stage at diagnosis, initial treatment choice, treatment with hormone therapy, institution, Gleason Score, PSA at diagnosis, date of diagnostic biopsy, season of diagnosis, and tobacco use history. Surgery consisted exclusively of radical retropubic prostatectomy, with or without nerve sparing technique. Radiation treatment consisted exclusively of brachytherapy. Initially, data were gathered on patients receiving external beam radiation, however, only 2 patient received external beam radiation out of the dataset. Therefore, this variable was not analyzed as part of this study.

The outcome is the initial treatment choice which consisted of three modalities.

The exposure variable was road distance traveled to the treatment facility. Distance was recorded as miles along roads from a starting location (which may be home, work or other) to the facility. The Zip code using Google measures one-way distance to facility.

We performed sensitivity analysis on the exposure by considering distance as a continuous variable and as a categorical variable.

As reported elsewhere [13] [14], we used 30 miles as a measure suggesting a "high" travel burden. We also chose 50 miles as the cutoff distant travel, representing approximately $1 \mathrm{~h}$ of travel time as done by others [15].

All variables underwent bivariate statistical analysis. Median values and range were calculated for all the continuous variables and frequency distributions were calculated for all the categorical variables. The comparisons of the initial treatment choice and demographics and clinical variables were performed using Kruskal-Wallis test for the continuous variables and with Chi-square test or Fisher's exact test for the categorical variables. Associations between distance traveled and initial treatment choice was analyzed using multivariable logistic regression models with generalized logit function adjusting for age at diagnosis, PSA at diagnosis, and the treatment facility. Statistics were performed using SAS (SAS Institute, Cary, NC, USA; Version 9.4 Users Guide). All the statistical tests were two-tailed with $\mathrm{p}<0.05$ considered to be significant.

\section{Results}

Medical records from 258 patients were initially reviewed. Six patients did not meet in- 
clusion criteria due to receipt of primary treatment out of state. Other reasons for exclusion were non-white race $(n=4)$, incorrect prostate cancer risk category $(n=3)$, insufficient medical records $(\mathrm{n}=2)$, and receipt of external beam radiation therapy (EBRT; $n=1)$. Final analysis included medical records of $(n=242) 147$ and 95 patients from St. Alexius and Sanford, respectively (Figure 1).

There was no significant association between initial treatment choice and mean travel distance to Bismarck Cancer Center (BCC). Whether or not a patient resided within the Bismarck/Mandan metro area was not significantly associated with initial treatment choice. Furthermore, when patients who did not live in the Bismarck/Mandan metro area were grouped according to distance from the BCC ( $\leq 75$ miles, $76-150$ miles, and $\geq 151$ miles), there was no significant association between distance group and initial treatment choice (Table 1).

Mean (standard deviation, SD) age at diagnosis among patients who received active surveillance, radical prostatectomy, or brachytherapy was 59.36 (4.11), 57.50 (4.24), and 59.42 (4.41), respectively $(\mathrm{p}<0.01)$. Those treated at St. Alexius accounted for 14 of 36 (39\%), 117 of 159 (74\%), and 16 of 47 (34\%) patients who received active surveillance, radical prostatectomy, or brachytherapy, respectively. Conversely, patients treated at Sanford accounted for $22(61 \%), 42(26 \%)$, and $31(66 \%)$, respectively $(\mathrm{p}<0.01)$. Overall, 117 of 147 of patients treated at St. Alexius underwent radical prostatectomy, compared to 42 of 95 at Sanford Health $(79.6 \%$ vs $44.2 \%$, p $<0.01)$.

Approximately $51 \%$ of patients treated with brachytherapy also received hormone therapy, while only $6 \%$ of patients receiving active surveillance and $4 \%$ of patients treated with radical prostatectomy received hormone therapy $(\mathrm{p}<0.01$, Table 1$)$. There was no significant association between initial prostate cancer treatment choice and race, tobacco use, or season at diagnosis. Additionally, prognostic indicators at diagnosis, including Gleason score, PSA, and clinical T stage, were not significantly associated with treatment choice.

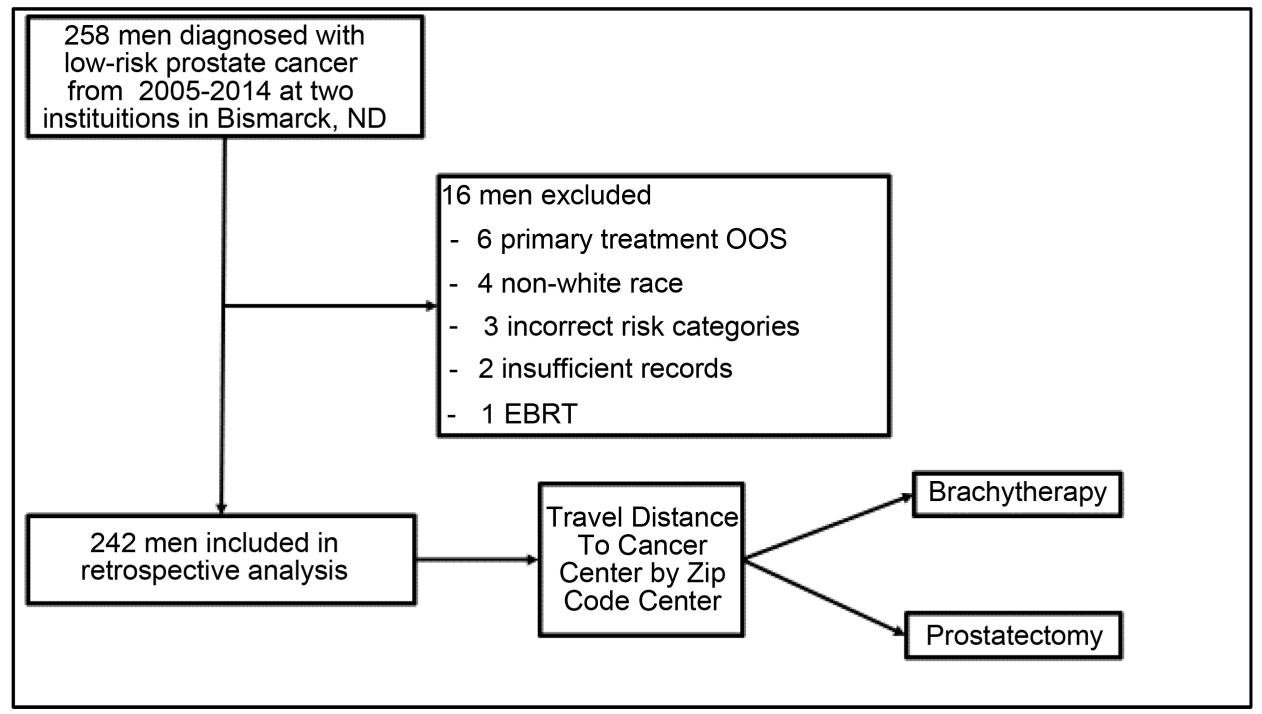

Figure 1. Study design. 
Table 1. Patient characteristics by initial treatment choice.

\begin{tabular}{|c|c|c|c|c|}
\hline \multicolumn{5}{|c|}{ Patient characteristics by initial treatment choice } \\
\hline \multirow[b]{2}{*}{$\begin{array}{l}\text { Continuous variable- } \\
\quad(\text { mean } \pm \text { SD })\end{array}$} & \multicolumn{3}{|c|}{ Treatment $(\mathrm{n}=242)$} & \multirow[b]{2}{*}{$\mathrm{p}$-value } \\
\hline & $\begin{array}{l}\text { Active surveillance } \\
\qquad(\mathrm{n}=36)\end{array}$ & $\begin{array}{l}\text { Radical prostatectomy } \\
\qquad(\mathrm{n}=139)\end{array}$ & $\begin{array}{l}\text { Brachytherapy } \\
\quad(\mathrm{n}=47)\end{array}$ & \\
\hline Age & $59.36 \pm 4.11$ & $57.50 \pm 4.24$ & $59.42 \pm 4.41$ & $\mathrm{p}=0.001^{\star}$ \\
\hline PSA & $5.75 \pm 2.08$ & $5.28 \pm 1.72$ & $6.04 \pm 1.72$ & $\mathrm{p}=0.055$ \\
\hline $\begin{array}{l}\text { Distance from } \\
\text { BCC }^{\star *}\end{array}$ & $101.98 \pm 39.41$ & $112.47 \pm 46.68$ & $113.26 \pm 39.41$ & $\mathrm{p}=0.563$ \\
\hline $\begin{array}{l}\text { Categorical } \\
\text { variable, n (\%) }\end{array}$ & & & & Chi-square \\
\hline Hormone therapy & $2(5.56)$ & $7(4.40)$ & $24(51.06)$ & $\mathrm{p}<0.0001^{\star}$ \\
\hline \multicolumn{5}{|l|}{ Institution } \\
\hline St. Alexius & $14(38.89)$ & $117(73.58)$ & $16(34.04)$ & \multirow{2}{*}{$\mathrm{p}<0.0001^{\star}$} \\
\hline Sanford & $22(61.11)$ & $42(26.42)$ & $31(65.96)$ & \\
\hline \multicolumn{5}{|l|}{ Residence } \\
\hline Bismarck metro & $18(50.00)$ & $68(42.77)$ & $16(34.04)$ & \multirow[b]{2}{*}{$\mathrm{p}=0.33$} \\
\hline $\begin{array}{l}\text { Not bismarck } \\
\text { metro }\end{array}$ & $18(50.00)$ & $91(57.23)$ & $31(65.96)$ & \\
\hline \multicolumn{5}{|l|}{ Distance from BCC } \\
\hline 0 - 75 miles & $24(66.67)$ & $88(55.35)$ & $22(46.81)$ & \multirow{3}{*}{$\mathrm{p}=0.43$} \\
\hline $76-150$ miles & $9(25.00)$ & $56(35.22)$ & $18(38.30)$ & \\
\hline$>151$ miles & $3(8.33)$ & $15(9.43)$ & $7(14.89)$ & \\
\hline \multicolumn{5}{|l|}{ Season } \\
\hline Winter & $4(11.11)$ & $43(27.04)$ & $11(23.40)$ & \multirow{4}{*}{$\mathrm{p}=0.33$} \\
\hline Spring & $16(44.44)$ & $49(30.82)$ & $12(25.53)$ & \\
\hline Summer & $8(22.22)$ & $39(24.53)$ & $12(25.53)$ & \\
\hline Fall & $8(22.22)$ & $28(17.61)$ & $12(25.53)$ & \\
\hline \multicolumn{5}{|l|}{ Tobacco use } \\
\hline Never & $21(60.00)$ & $74(50.00)$ & $25(56.82)$ & \multirow{3}{*}{$\mathrm{p}=0.32$} \\
\hline Former $(>1 \mathrm{yr})$ & $5(14.29)$ & $46(31.08)$ & $10(22.73)$ & \\
\hline Current & $9(25.71)$ & $28(18.92)$ & $9(20.45)$ & \\
\hline \multicolumn{5}{|l|}{ Gleason score } \\
\hline 5 & $0(0)$ & $2(1)$ & $0(0)$ & \multirow{2}{*}{$\mathrm{p}=1.0$} \\
\hline 6 & $36(100)$ & 157 (99) & $47(100)$ & \\
\hline \multicolumn{5}{|l|}{ Clinical stage } \\
\hline T1a & $1(3)$ & $2(1)$ & $0(0)$ & \multirow{4}{*}{$\mathrm{p}=0.18$} \\
\hline $\mathrm{T} 1 \mathrm{~b}$ & $0(0)$ & $1(1)$ & $0(0)$ & \\
\hline T1c & $30(83)$ & $149(94)$ & $42(89)$ & \\
\hline $\mathrm{T} 2 \mathrm{a}$ & $5(14)$ & $7(4)$ & $5(11)$ & \\
\hline
\end{tabular}




\section{Discussion}

Our results indicate that travel distance to the treatment facility was not associated with initial treatment choice. The results also indicate a possible institutional treatment bias favoring radical prostatectomy. It is unknown whether the patients who received surgery consulted with a radiation oncologist.

Our data contrast previous reports that have linked increased travel distance with decreased likelihood of receipt of radiation therapy for several different types of cancer [4] [5] [16]-[19]. Recently, Muralidhar et al. used the National Cancer Database to identify over 200,000 men diagnosed with low, intermediate, or high-risk prostate cancer treated with either prostatectomy or radiation. They report that patients living in urban or rural areas were less likely to receive radiation compared to surgery if they lived farther from the treatment facility, regardless of prostate cancer risk status and after adjusting for geographic location in the US [10].

The discrepancy between our results and the national trend suggests that in Bismarck, ND, factors other than travel distance may be relatively more influential in patient decision-making regarding treatment for low-risk prostate cancer. One such factor we identified was the institution at which patients were treated $(\mathrm{p}<0.01)$. Cooperberg et al. used a national registry of over 10,000 men with low-risk prostate cancer diagnosed between 1990 and 2013 to evaluate trends in management. They showed that national rates of radical prostatectomy decreased from around $60 \%$ in 2005 to around $50 \%$ in 2013 [19]. Rates of radical prostatectomy at St. Alexius for patients with low-risk prostate cancer in our analysis approached $80 \%$, well above the national rate during the same time period. On the other hand, the rate of radical prostatectomy at Sanford was approximately $44 \%$, slightly below the national average. Alternatively, it is possible that unaccounted for variables, like socioeconomic status or race affect stage and risk category of disease at presentation, and tend to correlate with travel burden on a broader national, but not universally local scale. 2014 median household income nationally in the US was $\$ 53,657$, while North Dakota's median household income was $\$ 55,579$ [20]. Our study's homogenously white population (only 4 of 257 patients were excluded for non-white race) and high median income may offset some effect burden of travel. This may be a topic of interest for future inquiry.

Patients treated with radical prostatectomy were, on average, almost two years younger than patients who received brachytherapy or active surveillance, which is consistent with national trends [21]. A potential explanation for this finding is that as patients age, they are less likely to be surgical candidates due to medical comorbidities. However, in this study, we did not collect data on patients' comorbidities, so a confident explanation for this observation cannot be provided.

A large prostate gland makes the technical aspects of brachytherapy implantation less feasible. Thus, a common clinical technique is to use neoadjuvant androgen suppression (i.e. "hormone therapy") to cytoreduce large prostates, despite several large retrospective studies failing to show improved cancer control outcomes with this technique [22]. The use of this practice likely explains the higher rate of receipt of hormone 
therapy observed among patients treated with brachytherapy in our study. Additionally, this study included only patients diagnosed with low-risk prostate cancer, which is defined by D'Amico criteria as: T-stage cT1a-cT2a; PSA $\leq 10$; Gleason score $\leq 6$ [23]. Given these strict criteria, there was little variability in each of these measures among all patients who met our inclusion criteria, which explains why our analysis did not reveal significant association between any of the prognostic indicators and initial treatment choice.

Our possible institutional bias toward radical prostatectomy at one of the 2 regional institutions included in the study highlights the discrepancy between institutional pattern of practice and national trends, and should serve to reinforce the consensus that the results of single-institution studies ought to be interpreted with caution. This bias may have resulted from the practice pattern of a single physician who was seeing most of the prostate cancer cases during the period of study analysis.

The retrospective nature of this study renders several limitations, including selection bias. Furthermore, there may be confounding factors affecting patient choice of treatment, such as medical comorbidities. In future studies, collection of comorbidity data would be useful in order to assess such potential confounding factors. As we demonstrated, institutional bias affected treatment choice. The use of zip code centroids for estimation of distance traveled rather than exact addresses underestimates road distances by $20 \%-30 \%$ [24].

Individual preferences play a central role in the decision whether to treat or to pursue active surveillance [25]. Treatment decision involvement was not available in the medical charts, therefore it is unknown who was responsible for the management decision: the patient alone; mainly the physician or both the patient and the doctor. Finally, compared with individuals living in urban areas, rural residents reported longer travel time to see a physician, particularly specialists [26]. This is particularly relevant to ND where extreme weather conditions in long winters and the rural roads can significantly inflate estimated travel times. The travel time information, as another proxy for travel burden, was unavailable to assess its impact on initial treatment choice.

\section{Conclusion}

In conclusion, our data did not show a relationship between treatment choice and travel distance in a rural state in men $<60$ years old diagnosed with low-risk prostate cancer. In addition, we found a possible institutional bias toward radical prostatectomy which could be physician specific.

\section{References}

[1] Siegel, R.L., Miller, K.D. and Jemal, A. (2016) Cancer Statistics. CA Cancer Journal for Clinicians, 66, 7-30. http://dx.doi.org/10.3322/caac.21332

[2] Thompson, I., Thrasher, J.B., Aus, G., et al. (2007) Guideline for the Management of Clinically Localized Prostate Cancer: 2007 Update. Journal of Urology, 177, 2106-2131. http://dx.doi.org/10.1016/j.juro.2007.03.003

[3] Wiegel, T., Stöckle, M. and Bartkowiak, D. (2015) Preference-Based Randomized Evalua- 
tion of Treatment Modalities in Low or Early Intermediate-Risk Prostate Cancer. European Urology, 67, 1. http://dx.doi.org/10.1016/j.eururo.2014.09.016

[4] Baldwin, L.M., Patel, S., Andrilla, C.H., Rosenblatt, R.A. and Doescher, M.P. (2012) Receipt of Recommended Radiation Therapy among Rural and Urban Cancer Patients. Cancer, 118, 5100-5109. http://dx.doi.org/10.1002/cncr.27488

[5] Celaya, M.O., et al. (2006) Travel Distance and Season of Diagnosis Affect Treatment Choices for Women with Early-Stage Breast Cancer in a Predominantly Rural Population (United States). Cancer Causes Control, 17, 851-856.

http://dx.doi.org/10.1007/s10552-006-0025-7

[6] Pucher, J. and Renne, J.L. (2004) Urban-Rural Differences in Mobility and Mode Choice: Evidence from the 2001 NHTS. Bloustein School of Planning and Public Policy, Rutgers University.

[7] Arcury, T.A., Preisser, J.S., Gesler, W.M. and Powers, J.M. (2005) Access to Transportation and Health Care Utilization in a Rural Region. Journal of Rural Health, 21, 31-38.

http://dx.doi.org/10.1111/j.1748-0361.2005.tb00059.x

[8] Coronado, G.D., Thompson, B., Koepsell, T.D., Schwartz, S.M. and McLerran, D. (2004) Use of Pap Test among Hispanics and Non-Hispanic Whites in a Rural Setting. Preventive Medicine, 38, 713-722. http://dx.doi.org/10.1016/j.ypmed.2004.01.009

[9] Probst, J.C., Laditka, S.B., Wang, J.Y. and Johnson, A.O. (2007) Effects of Residence and Race on Burden of Travel for Care: Cross Sectional Analysis of the 2001 US National Household Travel Survey. BMC Health Services Research, 7, 40.

http://dx.doi.org/10.1186/1472-6963-7-40

[10] Muralidhar, V., et al. (2016) Association between Travel Distance and Choice of Treatment for Prostate Cancer: Does Geography Reduce Patient Choice? International Journal of Radiation Oncology, Biology, Physics, 96, 313-317. http://dx.doi.org/10.1016/j.ijrobp.2016.05.022

[11] Baldwin, L.-M., Andrilla, C.H.A., Porter, M.P., Rosenblatt, R.A., Patel, S. and Doescher, M.P. (2013) Treatment of Early-Stage Prostate Cancer among Rural and Urban Patients. Cancer, 119, 3067-3075. http://dx.doi.org/10.1002/cncr.28037

[12] http://factfinder.census.gov/faces/tableservices/jsf/pages/productview.xhtml?pid=PEP_2015 PEPANNRES\&src $=\mathrm{pt}$

[13] Jacoby, I. (1991) Geographic Distribution of Physician Manpower: The GMENAC (Graduate Medical Education National Advisory Committee) Legacy. Journal of Rural Health, 7, 427-436.

[14] Ricketts, T.C., Savitz, L.A., Gesler, W.M. and Osborne, D.N. (1994) Geographic Methods for Health Services Research. University Press of America, Lanham.

[15] Onega, T., Duell, E.J., Shi, X., et al. (2008) Geographic Access to Cancer Care in the US. Cancer, 112, 909-918. http://dx.doi.org/10.1002/cncr.23229

[16] Liu, E., et al. (2015) A Quantitative Analysis of the Relationship between Radiation Therapy Use and Travel Time. International Journal of Radiation Oncology Biology and Physics, 93, 710-718. http://dx.doi.org/10.1016/j.ijrobp.2015.06.004

[17] Lin, C.C., et al. (2015) Association between Geographic Access to Cancer Care, Insurance, and Receipt of Chemotherapy: Geographic Distribution of Oncologists and Travel Time. Journal of Clinical Oncology, 33, 3177-3185. http://dx.doi.org/10.1200/JCO.2015.61.1558

[18] Goyal, S., et al. (2015) Effect of Travel Distance and Time to Radiotherapy on Likelihood of Receiving Mastectomy. Annals of Surgical Oncology, 22, 1095-1101. http://dx.doi.org/10.1245/s10434-014-4093-8 
[19] Cooperberg, M., et al. (2015) Trends in Management for Patients with Localized Prostate Cancer, 1990-2013. Journal of the American Medical Association, 314, 80-82.

http://dx.doi.org/10.1001/jama.2015.6036

[20] U. S. Census Bureau, American Community Survey (ACS) and Puerto Rico Community Survey (PRCS) (2015) 5-Year Estimates. State \& County Quickfacts, North Dakota. http://www.census.gov/quickfacts/table/PST045215/38

[21] Barqawi, A.B., et al. (2012) Current Challenges in Prostate Cancer Management and the Rationale behind Targeted Focal Therapy. Advances in Urology, 2012, Article ID: 862939. http://dx.doi.org/10.1155/2012/862639

[22] Nag, S., et al. (1999) American Brachytherapy Society (ABS) Recommendations for Transperineal Permanent Brachytherapy of Prostate Cancer. International Journal of Radiation Oncology, Biology, Physics, 44, 789-799. http://dx.doi.org/10.1016/S0360-3016(99)00069-3

[23] D’Amico, A.V. (2001) Combined-Modality Staging for Localized Adenocarcinoma of the Prostate. Oncology, 15, 1049.

[24] Fortney, R.K. and Warren, J. (2000) Comparing Alternative Methods of Measuring Geographic Access to Health Services. Health Services Outcomes Research Methodology, 1, 173-184. http://dx.doi.org/10.1023/A:1012545106828

[25] Hayes, J.H., Ollendorf, D.A., Pearson, S.D., et al. (2010) Active Surveillance Compared with Initial Treatment for Men with Low-Risk Prostate Cancer: A Decision Analysis. JAMA, 304, 2373-2380. http://dx.doi.org/10.1001/jama.2010.1720

[26] Reschovsky, J.D. and Staiti, A.B. (2005) Access and Quality: Does Rural America Lag behind? Health Affairs, 24, 1128-1139. http://dx.doi.org/10.1377/hlthaff.24.4.1128

\section{Submit or recommend next manuscript to SCIRP and we will provide best service for you:}

Accepting pre-submission inquiries through Email, Facebook, LinkedIn, Twitter, etc. A wide selection of journals (inclusive of 9 subjects, more than 200 journals)

Providing 24-hour high-quality service

User-friendly online submission system

Fair and swift peer-review system

Efficient typesetting and proofreading procedure

Display of the result of downloads and visits, as well as the number of cited articles

Maximum dissemination of your research work

Submit your manuscript at: http://papersubmission.scirp.org/

Or contact jct@scirp.org 